\title{
Fetal Cerebellar Vermis Assessment by MRI. What Does It Add?
}

\author{
Sarah M. Ragaee ${ }^{1}$, Mohamed Aboul-Fotouh Mourad', Soha Talaat Hamed ${ }^{2}$, Ahmed M. Abbas ${ }^{3^{*}}$ \\ ${ }^{1}$ Department of Radiology, Faculty of Medicine, Minia University, Minia, Egypt \\ ${ }^{2}$ Department of Radiology, Faculty of Medicine, Cairo University, Cairo, Egypt \\ ${ }^{3}$ Department of Obstetrics \& Gynecology, Faculty of Medicine, Assiut University, Assiut, Egypt \\ Email: *bmr90@hotmail.com
}

How to cite this paper: Ragaee, S.M., Mourad, M.A.-F., Hamed, S.T. and Abbas, A.M. (2019) Fetal Cerebellar Vermis Assessment by MRI. What Does It Add? Open Journal of Obstetrics and Gynecology, 9, 1290-1303.

https://doi.org/10.4236/ojog.2019.99125

Received: August 29, 2019

Accepted: September 22, 2019

Published: September 25, 2019

Copyright (C) 2019 by author(s) and Scientific Research Publishing Inc. This work is licensed under the Creative Commons Attribution International License (CC BY 4.0).

http://creativecommons.org/licenses/by/4.0/

\section{Open Access}

\begin{abstract}
Background: Posterior fossa anomalies (PFAs) are considered one of the commonest brain anomalies identified by the fetal imaging techniques. The current study aims to estimate the significance of cerebellar vermis assessment by fetal MRI in fetal brain malformations. Patients and Methods: The study was conducted at a tertiary University hospital in Upper Egypt. Data were gathered prospectively from sixty pregnant women with sonographically diagnosed fetal brain malformations referred for Magnetic Resonance Imaging (MRI) between April 2015 and May 2019 followed by postpartum neonatal MRI brain examination for non-terminated and live birth cases. Results: Of the sixty fetuses with brain malformations, additional cerebellar vermis findings were seen on MRI in 10 cases (16.6\%). Fetal MRI sensitivity, specificity, positive and negative predictive values were $100 \%$ that were in correlation with those of prenatal ultrasound turned out to be significantly higher. Conclusion: This study recommends fetal MRI for cerebellar vermis assessment in fetal brain malformations to guide the clinical management.
\end{abstract}

\section{Keywords}

Fetal MRI, Cerebellar Vermis, Prenatal Ultrasound, Vermian Abnormalities, Posterior Fossa Anomalies

\section{Introduction}

Posterior fossa anomalies (PFAs) are considered one of the commonest brain anomalies identified by the fetal imaging techniques [1]. No doubt that prenatal ultrasound (US) is the investigation of choice on screening for fetal abnormalities. However, regarding posterior fossa anomalies in specific, fetal US has li- 
mited specificity and false-positive diagnoses [2].

Fetal MRI has been shown to be a useful adjunct to ultrasound in suspected fetal anatomic abnormalities and especially used for fetal brain imaging [3] [4]. Fetal MRI has several advantages over US: It has higher contrast resolution, not affected by the shadowing from the calvarium, or by maternal obesity or low amniotic fluid volume. Also, it is more useful than US in late pregnancy [5].

The superiority of MRI to prenatal ultrasound in posterior fossa anomalies is owing to evaluation of different structures in the posterior fossa, where it determines vermian dysplasia or aplasia, the shape of the fourth ventricle, the insertion of the tentorium cerebella and if cerebellar compression presents [6]. In addition, it clearly depicts the retro-cerebellar space with better differentiation between Dandy Walker malformation (DWM), (Vermian Hypoplasia) VH, and Megalencephaly-capillary malformation (MCM), where each of which has a different prognosis [7].

The cerebellar vermis per se starts development as a thickening of the alar plate of the rhombencephalon during the fifth week of gestation [8]. By 18 to 19 weeks, the craniocaudal length of the vermis is equal to that of the cerebellar hemispheres, and the fourth ventricle is usually completely covered [9].

\section{Aim of the Work}

The aim of the work to put the spotlight upon the impact of cerebellar vermis assessment by fetal MRI upon management in fetal brain malformations.

\section{Patients and Methods}

This prospective study was approved by the ethics committee of our institution during the period between April 2015 and May 2019. The study was conducted at a tertiary University hospital in Upper Egypt and included 60 pregnant women with their age ranging from 18 to 45 years \& of gestational age ranging from 20 to 32 weeks. We performed fetal MRI to sonographically diagnosed fetal posterior fossa anomalies followed by postnatal MRI brain to $25 \%$ of our 60 cases, who weren't terminated \& were live birth.

\section{All the patients were subjected to: -}

1) Thorough history taking.

2) Family history.

3) Basic obstetric Sonography examination.

4) Detailed sonographic fetal CNS anomaly scan including 3D \& 4D ultrasound.

5) Fetal MRI brain.

6) Postnatal MRI brain to cases who were weren't terminated and were live birth.

\section{Inclusion criteria}

Sonographically diagnosed fetal brain malformations.

\section{Exclusion criteria}

- MRI contraindication (as cardiac pace maker) 
- Mother's refusal to do fetal MRI.

\section{U/S technique:}

As for the sonographic examination, it was done in supine position with her head slightly raised; using (Voluson E, Toshiba, Japan) with trans-abdominal transducer of a bandwidth $3.5 \mathrm{MHz}$ associated with color Doppler added property. First Basic obstetric sonographic examination will be done, followed by a detailed (2D/3D) fetal CNS anomaly scan with detection of other anomalies associated.

\section{MRI technique:}

MRI examination was performed on 1.5-Tesla MR scanner (Ingenia 1.5 Tesla, Philips, Netherland) using a multi-channel phased array coil to allow increased coverage of the fetal head and increased signal-to-noise ratio. The mother was made to lie supine or on her left side (if more comfortable) during the exam. In order to minimize fetal motion, the mother was made as comfortable as possible \& she fasted 4 hours prior to the MR exam. Because maternal or fetal sedation was not used, most fetal MRI was primarily performed using ultrafast T2-W sequences known as single-shot rapid acquisition with refocused echoes (i.e. single-shot fast spin-echo or half-Fourier acquired single-shot turbo spin-echo). Using these techniques, a single T2-W image was acquired in less than $1 \mathrm{~s}$, decreasing sensitivity to fetal motion with total scanning time about 4 - 5 minutes.

Typically, an initial localizer was obtained in three orthogonal planes with respect to the mother, using 6- to 8-mm thick slices with a 1- to 2-mm gap and a large field of view. TR $1500 \mathrm{~ms}$; TE $151 \mathrm{~ms}$; slice thickness $4 \mathrm{~mm}$; FOV $260 \AA$ 350 mm; matrix $192 \AA$ - 256;

\section{Image interpretation parameters:}

- The vermis should cover the $4^{\text {th }}$ ventricle by 18 - 19 weeks gestation, but initially may be slightly smaller inferiorly.

- Vermian anomalies were defined when measurements were abnormal based on standardized measurements described by Garel et al. (2004) and Robinson et al., 2007.

- The craniocaudal diameter was calculated on basis of the equation diameter $(\mathrm{mm})=0.74 \times$ gestational age (weeks) -6.11 as described by Robinson et al., 2007.

○ While the tegmento-vermian angle was considered abnormal if $>6^{\circ}-9^{\circ}$ as was stated by Robinson et al., 2007.

- Foliation of the vermis was evaluated and was noted to be normal for gestational age with the exception of those identified with DWMs and rhomben-cyphalo-synapsis cases.

- Our cases were diagnosed on that basis as follows:

$\circ$ DWM was diagnosed if complete agenesis of vermis.

$\circ$ DW variant was diagnosed if partial agenesis of vermis.

- Chiari II \&III malformations were diagnosed if cerebellar vermis is noted as a portion of downwards cerebellar herniation through the spinal canal. 
$\checkmark$ Rhombencyphalosynapsis was diagnosed if absent vermis with the cerebellar hemispheres closely opposed to each other, with transversely oriented inferior cerebellar folia and rounded shaped fourth ventricle.

\section{Statistical analysis}

Statistic Package for Social Sciences (SPSS v 17.0 for Windows, Chicago, IL) software was used for data analysis. Statistical significance was assessed using the chi square $\chi^{2}$ test as all data are expressed as nominal. Significance was interpreted as $\mathrm{p}<0.05$.

\section{Results}

Sixty pregnant females were enrolled in our study with their age ranging from 18 to 45 years of mean value about $27.5 \pm 8.3$ years. In addition our results revealed that about $80 \%$ of our pregnant females were above 35 years old which was statistically significant $(\mathrm{p}=0.041)$ (Table 1$)$.

Regarding the gestational age (GA) of the involved fetuses, it ranged from 20 to 32 weeks with mean value of $26 \pm 4.5$ weeks. Fetal MRI additional abnormalities (about 16.6\%) \& changing diagnosis (8.3\%) were more pronounced after 24 weeks GA (Figure 1). Before 24 weeks GA, Fetal MRI only confirmed the diagnosis with no additional abnormalities addressed (Table 2).

Table 3 shows the percent and classification of vermian anomalies in our study according to their associations. The associated cerebral anomalies (Corpus callosum dysgenesis, lissencephaly, VM, IH cyst, encephalocele) were found in $16.6 \%$ of cases.

Table 4 shows how the additional abnormalities concerning the cerebellar vermis-addressed by the fetal MRI-in our study impacts the management of the cases. Figures 2-6 show MRI features of some included cases in our study.

Table 1. Range \& mean value of maternal age in relation to CNS anomalies.

\begin{tabular}{ccccc}
\hline Maternal Age & Minimum to maximum & Range & Percent & $P$-value \\
\hline$>35$ years & $18-45$ years & $27.5 \pm 8.3$ & $80 \%$ & 0.041 \\
$<35$ years & & & $20 \%$ & \\
\hline
\end{tabular}

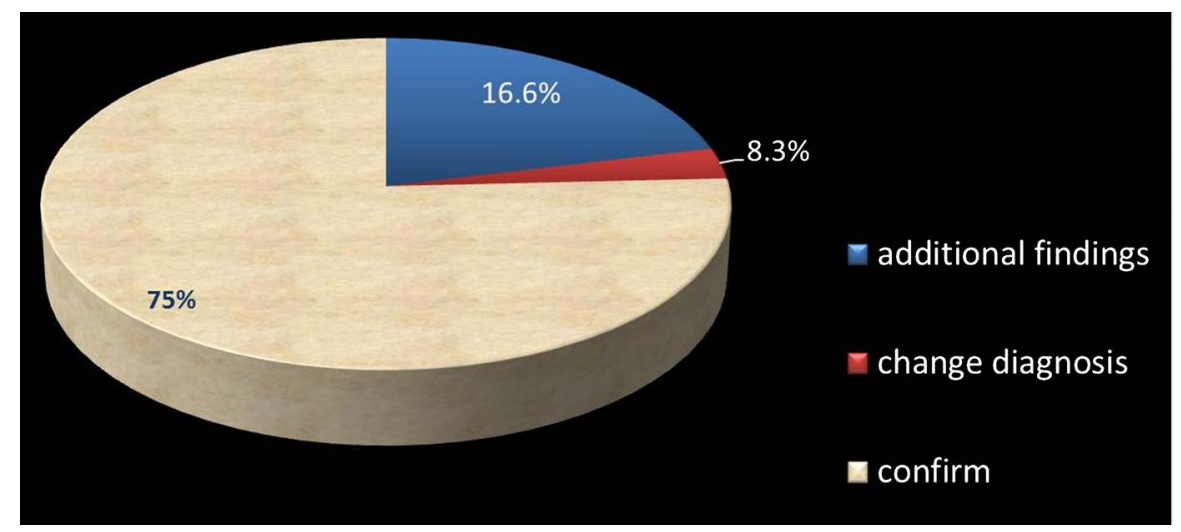

Figure 1. Pie chart diagram showing the percent of the additional findings, the confirmed sonographic diagnosis \& the percent of the changed US diagnosis by fetal MRI. 
S. M. Ragaee et al.

Table 2. Range and mean value of GA with relation to the additional findings by fetal MRI.

\begin{tabular}{ccccccc}
\hline \multicolumn{2}{c}{ Gestational age } & \multicolumn{2}{c}{ MRI over US } & \multirow{2}{*}{$P$-value } \\
\hline \multirow{2}{*}{ Minimum to maximum } & Range & & Add & Change diagnosis & Confirm & \\
\hline \multirow{2}{*}{20 to 32 weeks } & $26 \pm 4.5$ weeks & $>24$ weeks & $10(16.6 \%)$ & $5(8.3 \%)$ & $18(30 \%)$ & 0.016 \\
& & $<24$ weeks & 0 & 0 & $27(45 \%)$ \\
\hline
\end{tabular}

Table 3. Percent and classification of the vermian malformation noted according to the associations whether intra or extra-cranial.

\begin{tabular}{|c|c|c|c|c|c|c|}
\hline \multirow[t]{2}{*}{ Vermian malformation } & \multirow{2}{*}{$\begin{array}{l}\text { Total } \\
\text { number } \\
\text { by U/S }\end{array}$} & \multirow{2}{*}{$\begin{array}{l}\text { Total } \\
\text { number by } \\
\text { fetal MRI }\end{array}$} & \multicolumn{2}{|l|}{ Isolated PFAs } & \multicolumn{2}{|l|}{ Associations } \\
\hline & & & $\begin{array}{l}\text { Isolated } \\
\text { vermian } \\
\text { malformation }\end{array}$ & $\begin{array}{l}\text { Associated brain stem } \\
\text { malformations } \\
\text { (hypoplasia, or } \\
\text { aquiductal stenosis) }\end{array}$ & $\begin{array}{l}\text { Associated cerebral } \\
\text { anomalies. } \\
\text { (C.C dysgenesis, } \\
\text { lissencephaly, VM, IH } \\
\text { cyst, encephalocele) }\end{array}$ & $\begin{array}{l}\text { Associated extra-cranial anomalies } \\
\text { (spinaldysraphism with } \\
\text { meningocele, renal dysplasia, HSM. } \\
\text { Post urethral valve, imperforate } \\
\text { anus with limb anomalies) }\end{array}$ \\
\hline Number & 12 & 24 & 4 & 3 & 10 & 7 \\
\hline Percent from total cases & $20 \%$ & $40 \%$ & $6.7 \%$ & $5 \%$ & $16.6 \%$ & $11.6 \%$ \\
\hline
\end{tabular}

Table 4. Comparative study between fetal MRI and prenatal ultrasound with demonstration of the added findings, changed and confirmed diagnosis by fetal MRI.

\begin{tabular}{|c|c|c|c|c|c|}
\hline $\begin{array}{l}\text { Sonographic } \\
\text { diagnosis }\end{array}$ & Number & $\begin{array}{l}\text { Fetal MRI Cerebellar additional findings or } \\
\text { changed diagnosis }\end{array}$ & $\begin{array}{l}\text { Management based } \\
\text { on US diagnosis. }\end{array}$ & $\begin{array}{l}\text { Management based on fetal } \\
\text { MRI diagnosis. }\end{array}$ & $\begin{array}{l}\text { Postnatal MRI } \\
\text { for live-birth } \\
\text { non-terminate } \\
\text { d cases }\end{array}$ \\
\hline \multicolumn{6}{|c|}{ Post F malformations } \\
\hline $\begin{array}{l}\text { Small } \\
\text { retrocerebellar cyst }\end{array}$ & 1 & Partial vermian agenesis...DW variant & Follow up & Termination if not precious & As fetal MRI \\
\hline $\begin{array}{l}\text { Mega cisterna } \\
\text { magna }\end{array}$ & 1 & Global cerebellar and vermian hypoplasia & Follow up & Termination if not precious & As fetal MRI \\
\hline $\begin{array}{l}\text { Chiari } \\
\text { malformation }\end{array}$ & 7 & $\begin{array}{l}\text { - Degree of cerebellar herniation including the } \\
\text { vermis } \\
\text { - Demonstrate of exact site of encephalocele in } \\
\text { ChiariIII. } \\
\text { - Cerebral associations as corpus callosaldysgenesis } \\
\text { - Demonstration of exact site, size and content of } \\
\text { meningocele for proper prenatal or postnatal } \\
\text { surgery. }\end{array}$ & $\begin{array}{l}\text { Termination on } \\
\text { confirmation }\end{array}$ & $\begin{array}{l}\text { - Termination if not } \\
\text { precious baby, } \\
\text { - If precious baby; fetal MRI } \\
\text { additional findings will aid } \\
\text { in managmenet especially } \\
\text { in prenatal surgery. }\end{array}$ & As fetal MRI \\
\hline DW malformation & 6 & $\begin{array}{l}>\text { Confirmed vermian agenesis } \\
>\text { Corpus callosaldysgenesis }\end{array}$ & Termination & $\begin{array}{l}\text { Termination if was diagnosed } \\
\text { earlier and if not precious. }\end{array}$ & As fetal MRI \\
\hline \multicolumn{6}{|c|}{ Cortical malformation } \\
\hline $\begin{array}{l}\text { Lissencephaly with } \\
\text { VM and cleft lip }\end{array}$ & 1 & $\begin{array}{l}\text { Rhomboncephalosynapsis with C.C dysgenesis and } \\
\text { z-shaped brain stem...... Walker-Warburg } \\
\text { syndrome (WWS) or HARDE syndrome (AR) }\end{array}$ & $\begin{array}{l}\text { Termination if not } \\
\text { precious }\end{array}$ & $\begin{array}{l}\text { Lethal form of congenital } \\
\text { muscular dystrophy so } \\
\text { Termination }\end{array}$ & $\ldots \ldots \ldots \ldots$ \\
\hline \multicolumn{6}{|l|}{ Exencephaly } \\
\hline Hydranencephaly & 1 & $\begin{array}{l}\text { Pontocerebellar dysplasia.... } \\
\text { Fowler syndrome (AR) }\end{array}$ & Termination only & $\begin{array}{l}\text { Termination with Genetic } \\
\text { counseling which confirmed } \\
\text { the diagnosis. }\end{array}$ & --------- \\
\hline \multicolumn{6}{|l|}{ Midline anomalies } \\
\hline $\begin{array}{l}\text { Interhemispheric } \\
\text { cyst versus } \\
\text { schizencephaly }\end{array}$ & 3 & $\begin{array}{l}\text { Cerebellar and vermian compression by the cyst .... } \\
\text { confirmed inter-hemispheric cyst. }\end{array}$ & $\begin{array}{l}\text { Needs confirmation } \\
\text { as ... Follow up if cyst } \\
\text { versus termination if } \\
\text { schizencephaly }\end{array}$ & Follow up & As fetal MRI \\
\hline
\end{tabular}



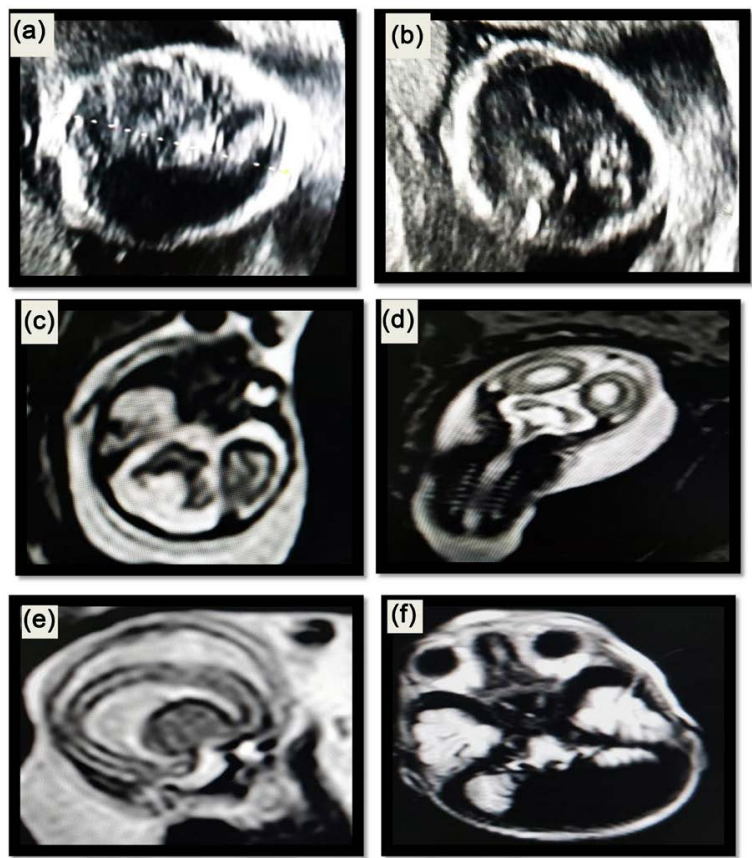

Figure 2. Fetus of 20 weeks GA, (a) and (b) US axial images revealing large posterior fossa with a retro-cerebellar cyst connected to the fourth ventricle ... DWM. ((c), (d) and (e)) MRI in axial, coronal and sagittal cuts confirming the diagnosis and adding the corpus callosal dysgenesis. (f) is postnatal MRI confirming the fetal MRI diagnosis.
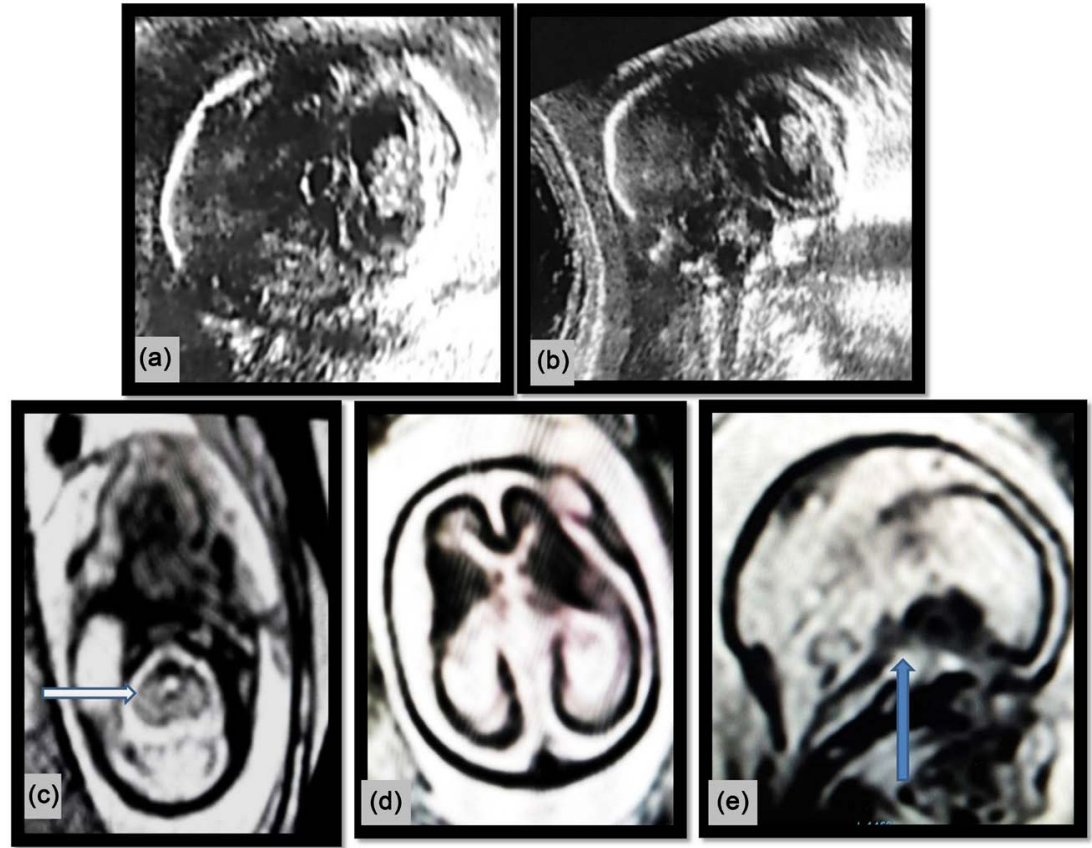

Figure 3. Fetus of 24 weeks GA (a) and (b) US axial and coronal images showing moderate supratentorial ventricular dilatation with smooth brain appearance... suggesting lissencephay. (c)-(e) MRI T2 WI in axial and sagittal planes confirming the diagnosis with adding rhombencephalosynapsis (absent vermis with globular shaped $4^{\text {th }}$ ventricle. white arrow), Z-shaped brain stem (blue arrow) and corpus callosal dysgenesis... rendering the diagnosis HARDE syndrome instead with the need for imminent termination as lethal anomaly and the need for genetic testing as AR. 


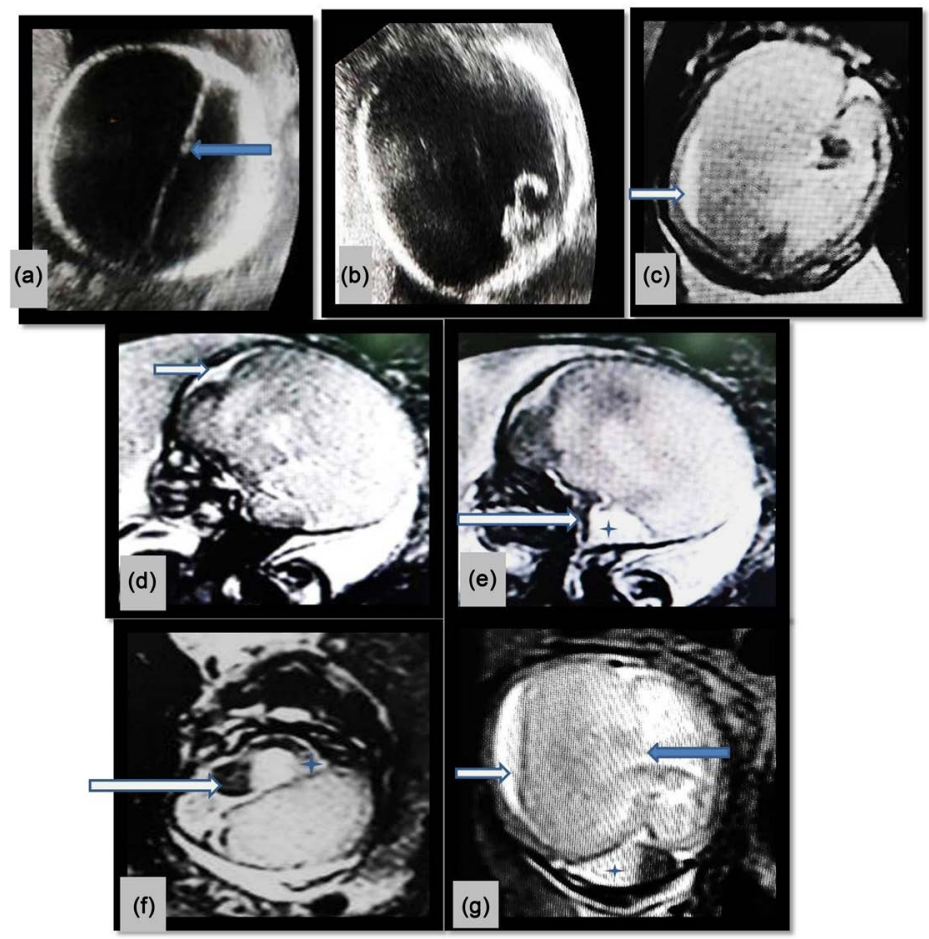

Figure 4. Fetus of 25 weeks GA, (a) and (b) US axial images showing CSF filled supratentorial sac with preserved falx suggesting hydranecephaly. (c)-(g) MRI in axial, sagittal and coronal cuts adding the vemian and unilateral cerebellar hemisphere agenesis rendering the diagnosis as Fowler syndrome instead, with the need for genetic testing as AR.
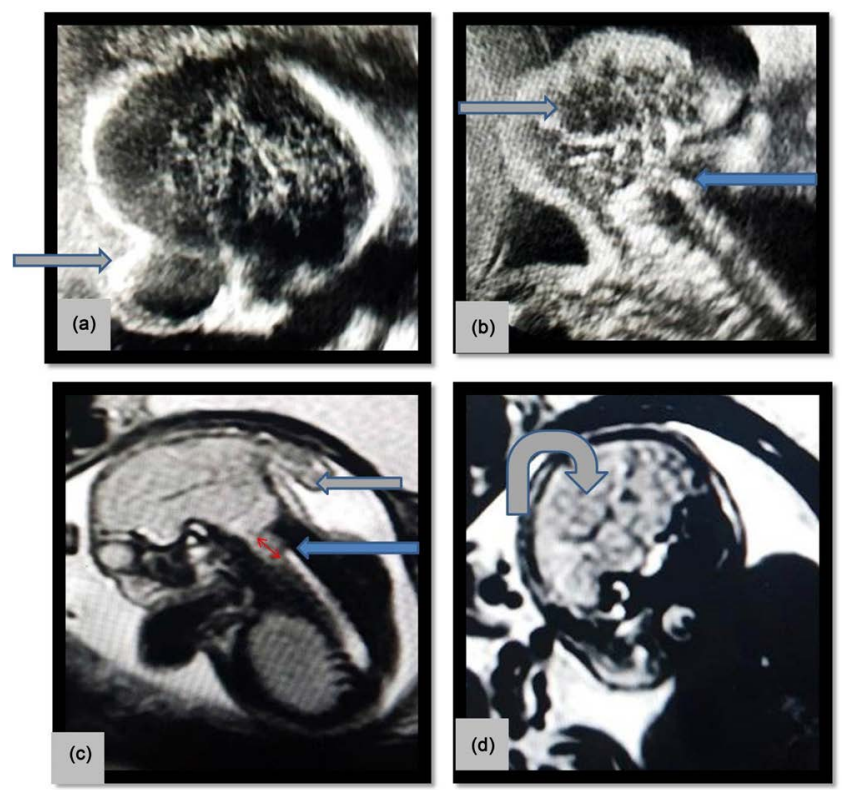

Figure 5. Fetal 26 weeks GA (a) and (b) US axial and coronal images showing occipital encephalocele(grey arrow) with cerebellar downwards herniation (blue arrow), Chiari III malformation.(c) and (d) MRI T2WI in sagittal and coronal planes confirming the diagnosis of Chiari III malformation, however determining the encephalocele to be posterior parietal not occipital (blue arrow), with adding the degree of downwards cerebellar vermis herniation (red arrow) and the corpus callosal dysgenesis (Viking helmet curved arrow). 

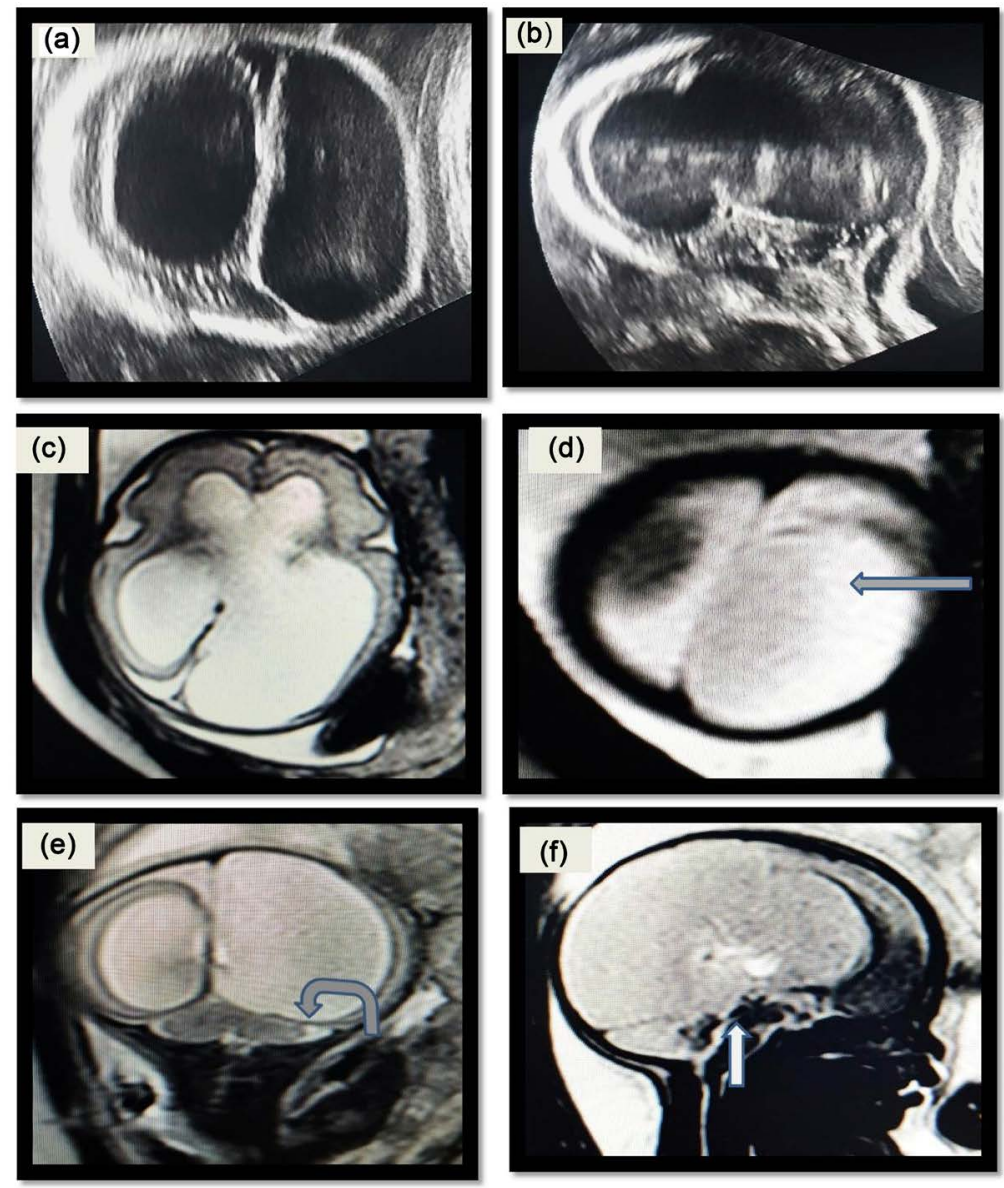

Figure 6. Fetus of 32 weeks GA, (a) and (b) U.S axial and coronal images showing asymmetrical supra-tentorial ventricular dilatation with suspected unilateral open lip schizencephaly versus interhemispheric cyst. (c)-(f) MRI in axial, coronal and sagittal cuts showing supratentorial ventricular dilatation with interhemispheric cystconfirmed by the cerebellar and vermian compression by the cyst (curved arrow). Moreover, aquiductal stenosis is added.

Table 5. The sensitivity, specificity, Negative \& Positive predictive value (NPV, PPV) of fetal MRI \& prenatal ultrasound in Fetal cerebellar vermis assessment.

\begin{tabular}{ccccc}
\hline & Sensitivity & Specificity & PPV & NPV \\
\hline Ultrasound & $60 \%$ & $86 \%$ & $84.5 \%$ & $54 \%$ \\
Fetal MRI & $100 \%$ & $100 \%$ & $100 \%$ & $100 \%$ \\
\hline
\end{tabular}

Lastly, Table 5 shows comparative study between US \& fetal MRI regarding the sensitivity, specificity, positive \& negative predictive values in our study, where they were about $100 \%, 100 \%, 100 \%$ \& $100 \%$ respectively for the MRI, while about $60 \%, 86 \%, 84.5 \%, 54 \%$ respectively for US, revealing superiority of MRI upon US regarding those items in fetal cerebellar vermis assessment.

\section{Discussion}

Despite the rapid progress in fetal imaging, the prenatal diagnosis of posterior 
fossa dysgenesis remains challenging due to both false-positive and false-negative diagnoses [10]. Proper fetal imaging in posterior fossa anomalies especially the vermis greatly aids in gathering accurate information which gives the base for reliable counseling. This counseling to parents is important both for obtaining appropriate knowledge of the potential outcomes in the neonate and child and for making informed decisions regarding future management of the pregnancy [11].

When an intracranial abnormality is detected on US specifically within the posterior fossa, a fetal MRI is the next investigation of choice. MRI assessment of the cerebellum and the vermis is based on morphological and biometrical data [12]. Fetal MRI provides accurate characterization and diagnosis of the fetal brain abnormality along with better detection of the differential diagnosis of vermian pathology [13].

The maternal age in our study was of significance; where $80 \%$ of our patients were older than 34 years old which denoted that advanced maternal age is directly proportional to increased risk of congenital anomalies including CNS anomalies. That was equivalent to the study conducted by Hollier et al., 2000 [14], who reported that advanced maternal age beyond 25 years old was associated with significantly increased risk of fetuses having congenital malformations. However, this was in contradiction to the study conducted by Goetzinger et al., 2014 [15], who stated that advanced maternal age was associated with a lower risk for major fetal anomalies. This contradiction is probably attributed to racial differences.

Regarding our cases, Cerebellar vermian malformations accounted for one of the most common brain malformations, where they accounted for about $40 \%$ of the fetal brain anomalies based on fetal MRI diagnosis in our study. This result was in rapprochement to the study addressed by Llorens Salvador et al., 2017 [16] who stated that cerebellar malformations are common and better detected by fetal MRI in the second half of pregnancy when ultrasound is deficient.

Fetal MRI additional findings were more pronounced after 24 weeks GA which was in coherence with and based on what was postulated by ACR, 2010 [17], that fetal MRI study may give limited diagnostic information in early gestational age due to the small size of the fetus and fetal movement.

The Vermian malformations in our study were nearly categorized on basis of fetal MRI according to their associations, either as a part of isolated posterior fossa malformations which was further classified into isolated vermian dysgenesis or associated with brain stem abnormalities as pontine hypoplasia or aquiductal stenosis ((which accounted for $6.7 \%$ and $5 \%$ of cases respectively). The second category was those associated with cerebral malformations as VM, corpus callosal dysgenesis, lissencephaly, periventricular heterotopia or interhemipheric cyst (accounting for about $16.6 \%$ of total cases). Then the third category was those with associated extra-cranial malformations as spinal dysraphism, renal dysplasia, posterior urethral valve, imperforate anus or limb anomalies 
(about $11.6 \%$ of total cases). This categorization is crucial;for it has a great influence upon the neurodevelopmental outcome of the fetuses as formerly proved by other studies as that of Patek et al., 2012 [18] which stated that associated brain stem abnormalities with vermian hypoplasia rendered the outcome much worse than isolated vermian hypoplasia. An exception for this rule is the DWM (Dandy Walker Malformation) which associated with poor outcome irrelevant of the associated brain stem abnormalities. In addition, the associated cerebral or extra-cranial abnormalities aids in determining the outcome and the supposed management.

Similar to previous studies, our results revealed that accurate depiction of vermis proved to be better by fetal MRI rather than prenatal ultrasound, where fetal MRI added cerebellar findings in 10 cases out of 60 (16.6\%), while it changed diagnosis of prenatal ultrasound in 4 cases out of 60 (8.3.\%) and confirmed the diagnosis of $75 \%$ of the cases. The study of Amaresh Indravadan et al., 2012 [19] also agreed with that, where he noted that there was superiority of MRI over antenatal US in diagnosing both common and unusual posterior fossa abnormalities in his study. Also the study of Limperopoulos et al., 2008 [2] which stated that antenatal MRI has advanced their ability to define major posterior fossa anomalies in the fetus. Likewise that was in rapprochement to what was stated in the study of Robinson et al., 2007 [6].

The results in our study has proven that reliable and proper assessment of vermis in fetal brain malformations tremendously impact the management of the cases; where some cases were misinterpreted by US as being retro-cerebellar cyst or mega cisterna magna, and proved by fetal and postnatal MRI to be partial vermian agenesis or vermian hypoplasia (Dandy Walker variant), that changed the management from just follow up to termination if not precious baby as this will impact the baby's neurodevelopmental outcome. So we can safely say that fetal MRI can be used for differentiating variable conditions in the retro-cerebellar space with subsequent different management of each. That was in agreement with what was reported by Limperopoulos et al., 2006 [7] in her study where she stated that fetal MRI clearly depicts the retro-cerebellar space with better differentiation between DWM, VH, and MCM, where each of which has a different prognosis.

Like-wise, we figured out that Fetal MRI vermian and cerebellar assessment; turned out to be also helpful in differentiating two supratentorial entities as well; the postero-inferiorly located open lip schizencephaly and interhemispheric cyst, where the latter performs compression upon the surrounding brain structures including the cerebellum and vermis if located postero-inferior; unlike the open lip schizencephaly which is evident in terms of fetal MRI.

Regarding Chiari malformations, in addition to confirming the diagnosis, Fetal MRI determine the degree of cerebellar herniation, the size, site and content of the meningocele and the exact site and size of the encephalocele if Chiari III. Moreover, it determines if there are cerebral structural associations as corpus 
callosal dysgenesis. All these information aid in the management of the fetuses especially nowdays with the ongoing advances in the prenatal surgery of spina bifida which definitely improve the hind brain herniation. That was in accordance to what was stated in the study of NielsGeerdink., et al. [20] who stated that based on some essential features (which are downward cerebellar and vermian herniation, medullary, pontine, and fourth ventricular downward displacement, medullary kinking, abnormally shaped fourth ventricle, hypoplastic tentorium, and beaked mesencephalictectum), MR assessment of Chiari malformations provides a consensus on the diagnosis

In addition to aiding in management and prediction of the neurodevelopmental outcome, we also noted that fetal MRI additional abnormalities regarding the cerebellar vermis give a clue about the possibility of recurrence \& the need for genetic testing in the diagnosed fetal brain malformations. An example for these two cases in our study which were formerly diagnosed by US as hydranencephaly and lissencephaly; On the other hand fetal MRI cerebellar and vermian additional findings rendered the diagnoses as Fowler and Walker Warburg (HARDE) syndrome respectively; which were proved to be autosomal recessive syndromes with the imminent need for genetic testing. That was in agreement with what was postulated by TejaswiKandula et al., 2015 [21] in his study; where he stated that additional findings by fetal MRI to prenatal ultrasound in fetal brain malformation said in the detection of the recurrence rate and the genetic testing if needed.

We have performed confirmatory postnatal MRI for cases which were not terminated \& were live birth (about 25\%) which revealed almost the same fetal MRI findings with almost nil additional findings. That rendered the fetal MRI sensitivity \& specificity in assessment of vermian abnormalities far beyond that of ultrasound with high MRI positive \& negative predictive value nearly about 100\%, coping with the study conducted by Trompoukis et al., 2012 [22] which came to a conclusion that fetal MRI provides more accurate diagnosis compared to ultrasound examination with fetal MRI sensitivity, specificity and positive predictive value as a screening tool approaches $100 \%$. Moreover that was to a great extent identical to what was postulated by Hamisa et al., 2013 [23] in her study where she found out that fetal MRI is useful as a complementary modality to 2D/4D Ultrasound in diagnosis of fetal CNS anomalies with specificity, positive \& negative predictive values about $100 \%$.That didn't match the study conducted by Malinger et al., 2002 [24] who rightfully criticized that the past reports describing superiority of MRI over ultrasound may have been biased because a comparison was made with routine trans-abdominal US without confirmatory tertiary level ultrasound examination, especially by trans-vaginal sonography.

Regarding the similarity in the results between the fetal MRI and the postnatal MRI; we came to a conclusion in our study that no demanding need for performing postnatal MRI for confirmation in cases of vermian abnormalities. That was in contrary to what was concluded by Limperopoulos et al., 2008 [2] in her 
study where she stated that their findings strongly support the need for postnatal MRI follow-up in cases with suspected posterior fossa anomalies by fetal MRI.

Limitations in our study included the relatively narrowed number of the performed postnatal MRI owing to the high ratio of termination decision, IUFD and still birth of our cases, in addition, the study needed to be applied on a larger cohort of pregnant women with fetal brain malformations which will be considered in the next study.

Our recommendations in the future is adding fetal MRI to prenatal ultrasound in fetal brain malformations to well assess the cerebellar vermis; where it is of great sensitivity \& specificity compared to the prenatal ultrasound \& it greatly manipulates the fetal management with better demonstration of the fetal and child's neurodevelopmental outcome.

\section{Conclusion}

Accurate antenatal diagnosis of the posterior fossa malformations is still a diagnostic challenge. Proper cerebellar vermis assessment by Fetal MRI, greatly manipulates management of fetal brain malformations and determines the fetal outcome where it proved better than prenatal ultrasound in reaching the correct diagnosis. In addition, similarity between fetal MRI and postnatal MRI in findings rendered usage of post natal MRI as a confirmatory tool of limited need.

\section{Conflicts of Interest}

The authors declare no conflicts of interest regarding the publication of this paper.

\section{References}

[1] Adamsbaum, C., Moutard, M.L., Andre, C., et al. (2005) MRI of the Fetal Posterior Fossa. Pediatric Radiology, 35, 124-140. https://doi.org/10.1007/s00247-004-1316-3

[2] Limperopoulos, C., Robertson, R.L., Khwaja, et al. (2008) How Accurately Does Current Fetal Imaging Identify Posterior Fossa Anomalies? American Journal of Roentgenology, 190, 1637-1643. https://doi.org/10.2214/AJR.07.3036

[3] Benacerraf, B.R., Shipp, T.D., Bromley, B. and Levine, D. (2007) What Does Magnetic Resonance Imaging Add to the Prenatal Sonographic Diagnosis of Ventriculomegaly? Journal of Ultrasound in Medicine, 26, 1513-1522. https://doi.org/10.7863/jum.2007.26.11.1513

[4] Levine, D., Barnes, P.D., Robertson, R.R., Wong, G. and Mehta, T.S. (2003) Fast MR Imaging of Fetal Central Nervous System Abnormalities. Radiology, 229, 51-61. https://doi.org/10.1148/radiol.2291020770

[5] Glenn, O.A. (2010) MR Imaging of the Fetal Brain. Pediatric Radiology, 40, 68-81. https://doi.org/10.1007/s00247-009-1459-3

[6] Robinson, A.J., et al. (2007) The Fetal Cerebellar Vermis: Assessment for Abnormal Development by Ultrasonography and Magnetic Resonance Imaging. Ultrasound Quarterly, 23, 211-223. https://doi.org/10.1097/01.ruq.0000263841.69689.a7

[7] Limperopoulos, C. and Du Plessis, A.J. (2006) Disorders of Cerebellar Growth and Development. Current Opinion in Pediatrics, 18, 621-627. 
https://doi.org/10.1097/MOP.0b013e32801080e8

[8] Zalel, Y., Seidman, D.S., Brand, N., et al. (2002) The Development of the Fetal Vermis: An In-Vivo Sonographic Evaluation. Ultrasound in Obstetrics \& Gynecology, 19, 136-139. https://doi.org/10.1046/j.0960-7692.2001.00621.x

[9] Babcook, C.J., Chong, B.W., Salamat, M.S., et al. (1996) Sonographic Anatomy of the Developing Cerebellum: Normal Embryology Can Resemble Pathology. American Journal of Roentgenology, 166, 427-433. https://doi.org/10.2214/ajr.166.2.8553961

[10] Siebert, J.R. (2006) A Pathological Approach to Anomalies of the Posterior Fossa. Birth Defects Research Part A: Clinical and Molecular Teratology, 76, 674-684. https://doi.org/10.1002/bdra.20296

[11] Bromley, B., Nadel, A.S., Pauker, S., Estroff, J.A. and Benacerraf, B.R. (1994) Closure of the Cerebellar Vermis: Evaluation with Second Trimester US. Radiology, 193, 761-763. https://doi.org/10.1148/radiology.193.3.7972820

[12] Patel, S. and Barkovich, A.J. (2002) Analysis and Classification of Cerebellar Malformations. American Journal of Neuroradiology, 23, 1074-1087.

[13] Katorza, E. and Bertucci, X.E. (2016) Development of the Fetal Vermis: New Biometry Reference Data and Comparison of 3 Diagnostic Modalities-3D Ultrasound, 2D Ultrasound, and MR Imaging. American Journal of Neuroradiology, 37, 13591366. https://doi.org/10.3174/ajnr.A4725

[14] Hollier, L.M. and Leveno, K.J. (2000) Maternal Age and Malformations in Singleton Births. Obstetrics \& Gynecology, 96, 701-706. https://doi.org/10.1097/00006250-200011000-00011

[15] Goetzinger, K.R., et al. (2017) Advanced Maternal Age and the Risk of Major Congenital Anomalies: Survival of the Fittest. American Journal of Perinatology, 34, 217-222. https://doi.org/10.1055/s-0036-1585410

[16] Llorens Salvador, R. and Viegas Sainz, A. (2017) Evaluation of the Fetal Cerebellum by Magnetic Resonance Imaging. Radiología, 59, 380-390. https://doi.org/10.1016/j.rxeng.2017.08.002

[17] American College of Radiology (ACR), Society for Pediatric Radiology (SPR) (2010) ACR-SPR Practice Guideline for the Safe and Optimal Performance of Fetal Magnetic Resonance Imaging (MRI). American College of Radiology, Reston, 10.

[18] Patek, K.J. and Kline-Fath, B.M. (2012) Posterior Fossa Anomalies Diagnosed with Fetal MRI: Associated Anomalies and Neurodevelopmental Outcomes. Prenatal Diagnosis, 32, 75-82. https://doi.org/10.1002/pd.2911

[19] Ranchod, A.I. (2012) Fetal MRI for Characterising a Variety of Posterior Fossa Anomalies Suspected on 3rd Trimester Ultrasound Examination-A Short Series of 4 Case. SA Journal of Radiology, 16, 27-29.

[20] Geerdink, N. and van der Vliet, T. (2012) Essential Features of Chiari II Malformation in MR Imaging: An Interobserver Reliability Study. Child s Nervous System, 28, 977-985. https://doi.org/10.1007/s00381-012-1761-5

[21] Tejaswi, K. and Michael, F. (2015) Isolated Ventriculomegaly on Prenatal Ultrasound: What Does Fetal MRI Add? Journal of Medical Imaging and Radiation Oncology, 59, 154-162. https://doi.org/10.1111/1754-9485.12287

[22] Trompoukis, P. and Papantoniou, N. (2012) Fetal MRI: Is It Really Helpful? The Journal of Maternal-Fetal \& Neonatal Medicine, 25, 2363-2368. https://doi.org/10.3109/14767058.2012.696161

[23] Hamisa, M., Dabees, N., Ataalla, W.M. and Ziada, D.H. (2013) Magnetic Resonance 
Imaging versus Ultrasound Examination in Detection of Prenatal Fetal Brain Anomalies. The Egyptian Journal of Radiology and Nuclear Medicine, 44, 665-672. https://doi.org/10.1016/j.ejrnm.2013.05.004

[24] Malinger, G., Lev, D. and Lerman-Sagie, T. (2002) Is Fetal Magnetic Resonance Imaging Superior to Neurosonography for Detection of Brain Anomalies? Ultrasound in Obstetrics \& Gynecology, 20, 317.

https://doi.org/10.1046/j.1469-0705.2002.00825.x 